\title{
ELABORAÇÃO DE CARTAS DE ZONEAMENTO GEOTÉCNICO: EXEMPLO DA FOLHA DE PIRACICABA, SÃO PAULO - ESCALA: 1.100 .000
}

\author{
Osni José PEJON \\ Lázaro Valentin ZUQUETTE
}

\section{RESUMO}

Este artigo mostra a importância da elaboração de cartas de zoneamento geotécnico geral em mapeamentos geotécnicos regionais. Apresenta-se neste trabalho a metodologia utilizada na elaboração da carta de zoneamento geotécnico geral da folha de Piracicaba na escala 1:100.000. Verifica-se a importância da utilização de atributos naturais para definição das unidades, devido ao inter-relacionamento que apresentam com os demais atributos.

\section{ABSTRACT}

This work presents the general engineering geological zoning map of the Piracicaba region at the 1:100.000 scale and the rules adopted for the elaboration of this graphic document in regional engineering geological mapping. Other aspects are discussed, such as the importance of the general engineering geological zoning map in the elaboration of other most specific maps and the fundamental attributes.

\section{INTRODUÇÃO}

O processo de zoneamento geotécnico se adapta perfeitamente aos mapeamentos em escalas pequenas, destinados ao planejamento, por abordar os componentes em associações de atributos que refletem as condições naturais do meio físico.

O zoneamento geotécnico vem sendo utilizado até em escalas muito pequenas, a nível mundial (ERSHOVA \& SERGEEV, 1979). Estes autores apresentaram os princípios do zoneamento geotécnico tipológico da Terra, na escala 1:15.000.000. Alguns trabalhos foram realizados abrangendo todo um país, como o de RADBRUCH-HALL et al. (1979), que realizaram o mapa geotécnico dos Estados Unidos na escala 1:7.500.000.

Os zoneamentos geotécnicos são também muito utilizados para subsidiar o planejamento regional em escalas 1:100.000 ou 1:50.000. DEARMAN et al. (1979) apresentam um zoneamento geotécnico da região de Tyne a Wear, na Inglaterra, obtido por sobreposição simples das informações de espessura dos depósitos superficiais, presença de material rochoso e profundidade do topo rochoso. Os mapas geotécnicos foram produzidos na escala 1:50.000 e a carta de zoneamento, na escala 1:200.000. HUMBERT, 1973 elaborou a carta geotécnica de Clermont-Ferrand, na escala 1:50.000, que constitui um exemplo típico de aplicação das cartas de zoneamento geotécnico ao planejamento regional.

Pelo exposto, fica evidente a importância das cartas de zoneamento geotécnico geral e específico, sua aplicabilidade às mais diversas situações de meio físico, podendo ser utilizadas desde escalas muito reduzidas, a nível de país, até escalas da ordem de 1:50.000, em planejamento regional.

Portanto, apresenta-se neste trabalho a metodologia utilizada para a elaboração da carta de zoneamento geotécnico geral da Folha de Piracicaba, Estado de São Paulo, na escala $1: 100.000$, baseada em atributos naturais do meio físico.

\section{LOCALIZAÇÃO DA ÁREA ESTUDADA}

A área estudada localiza-se na região centro-leste do Estado de São Paulo, entre os paralelos $22^{\circ} 30^{\prime}$ e $23^{\circ} 30^{\prime} \mathrm{S}$ e os meridianos $47^{\circ}$ $30^{\prime}$ e $48^{\circ} 00^{\prime}$, correspondendo a uma área de aproximadamente $2.900 \mathrm{~km}^{2}$.

\section{MÉTODOS DE OBTENÇÃO DAS CARTAS DE ZONEAMENTO}

As cartas de zoneamento geotécnico normalmente são obtidas por simples sobreposição ou por meio de uma hierarquização de fatores. 
a) Método da sobreposição

Por este método, os documentos gráficos básicos (mapas e cartas), que representam os atributos dos componentes do meio físico, são sobrepostos, de maneira a estabelecer as novas unidades (COELHO, 1980).

A sobreposição pode resultar em cartas de zoneamento, onde as unidades são totalmente redefinidas e os atributos das novas unidades passam a ser o resultado da fusão e interpretação das informações existentes, consistindo em um processo de generalização tipológica (VARNES, 1974).

A maior parte das cartas de zoneamento geotécnico geral corresponde a cartas de sobreposição simples (COELHO, 1980), onde as novas unidades são representadas pelo somatório das informações contidas nas unidades originais com igual peso. As cartas de zoneamento geotécnico com finalidades específicas, por exemplo, carta de risco à erosão, também podem ser produzidas por sobreposição de informações e mapas, mas, normalmente, são feitas a interpretação e fusão dos dados existentes, originando novas unidades com limites e atributos redefinidos. Neste caso os diferentes atributos, provenientes de cada mapa básico, em geral têm pesos diferentes, que são função de sua importância na caracterização da nova unidade, relacionada à finalidade da carta. Assim, em uma carta deste tipo não constam da legenda de cada unidade os atributos que the

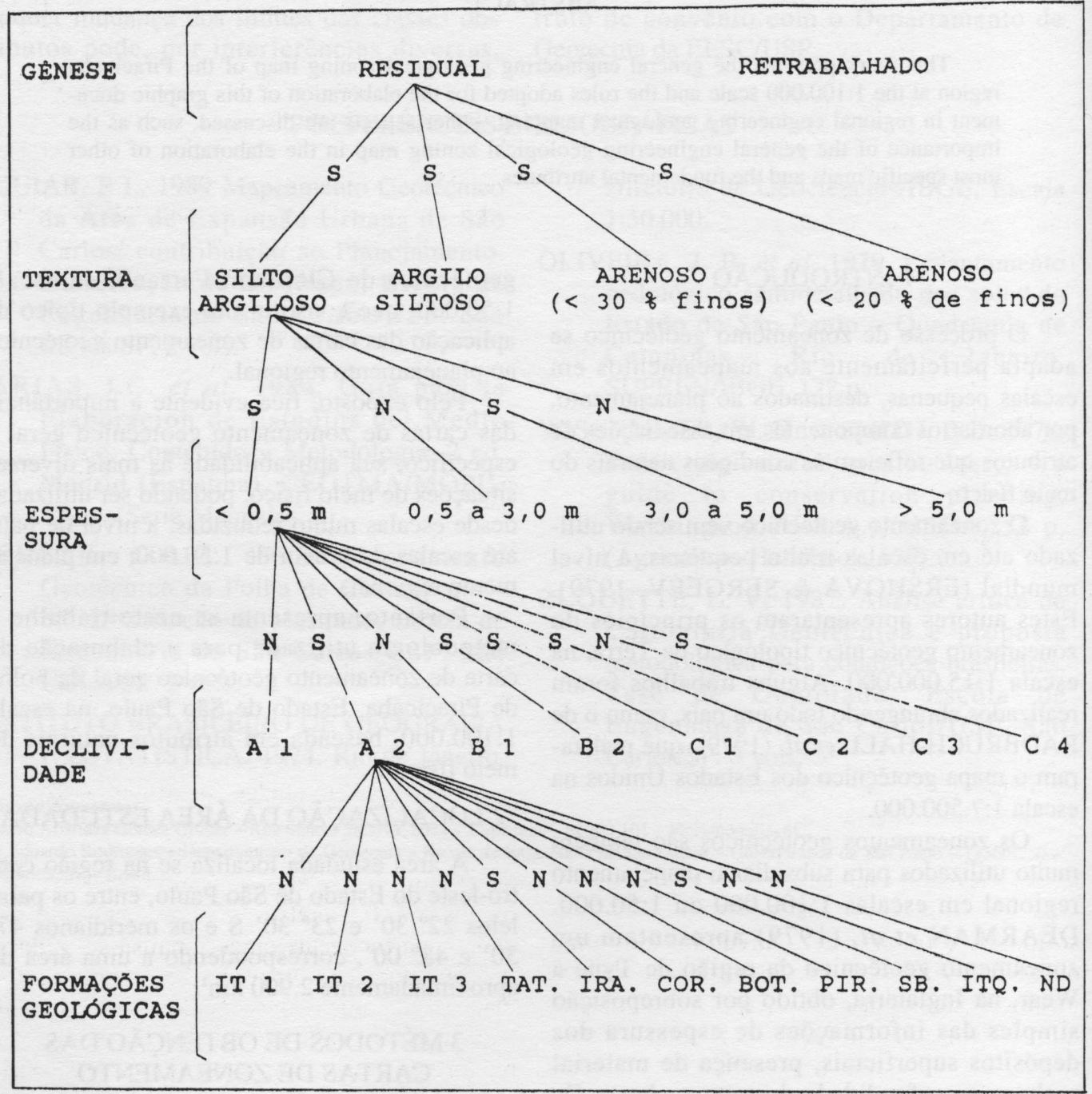

FIGURA 1 - Exemplo de definição das unidades da área mapeada utilizando-se o método da árvore lógica. 
deram origem, mas sim a interpretação que, no exemplo citado, corresponderia a indicar as áreas mais ou menos susceptíveis à erosão.

Uma grande vantagem do método da sobreposição simples é também permitir com facilidade o uso de métodos computacionais na elaboração das cartas de zoneamento geotécnico.

b) Método baseado em uma hierarquia de fatores e atributos

As unidades de zoneamento são definidas em função de uma hierarquia de atributos relacionados à escala e às características do meio físico, constituindo assim unidades taxonômicas. Essa maneira de elaboração das cartas de zoneamento é adotada pela proposta IAEG-UNESCO (1976), onde é definida uma seqüência de atributos a serem analisados em cada nível.

\section{ELABORAÇÃO DA CARTA DE ZONEAMENTO GEOTÉCNICO GERAL DA FOLHA DE PIRACICABA}

A carta foi elaborada por meio da sobreposição de informações dos mapas do substrato rochoso, dos materiais inconsolidados e da carta de declividade generalizada (PEJON, 1992). A sobreposição destes documentos gráficos permitiu a definição de zonas caracterizadas por: textura, espessura e gênese dos materiais inconsolidados, declividade e tipo de substrato rochoso. A importância destes atributos foi estudada em matrizes do tipo atributo $\mathrm{x}$ atributo, onde se verificou que apresentavam relação com mais de $50 \%$ dos demais atributos do meio físico. Portanto, pressupõe-se que uma carta de zoneamento geotécnico geral, obtida pela sobreposição simples desses atributos, permite o estabelecimento de unidades (zonas) com características bastante uniformes em termos de uma série de propriedades geotécnicas.

\subsection{Definição das unidades de zoneamento}

A combinação dos cinco atributos anteriormente citados possibilita o estabelecimento de um número muito elevado de unidades. Quanto à gênese, os materiais foram classificados em duas classes, quanto à textura e espessura, em quatro classes. O número de formações geológicas que pode ter originado os materiais inconsolidados é igual a dez, havendo mais uma opção para o caso da não-identificação da formação à qual estaria associado o material. $\mathrm{O}$ número de classes de declividade é igual a oito, resultando, portanto, na possibilidade de estabelecimento de 2.816 unidades diferentes.

Desta forma, optou-se pelo uso do método da árvore lógica para a definição das unidades que realmente podem existir. Na Fig. 1 apre- senta-se um exemplo de definição das unidades de zoneamento.

O método da árvore lógica prevê a análise de todas as situações de combinação teoricamente possíveis. Algumas destas combinações devem ser excluídas por não serem possíveis; por exemplo, materiais arenosos residuais de argilitos, ou ao contrário, materiais residuais argilosos de arenitos. Desta forma, as combinações logicamente possíveis recebem um "sim" e as não-possíveis um "não" e a análise interrompe-se neste ponto.

As combinações logicamente possíveis devem ser comparadas com a realidade da área mapeada para verificação de sua ocorrência ou não. Caso ocorram, recebem um "sim"; caso contrário, um "não" e o processo de análise pára neste ponto.

No exemplo da figura 1 inicia-se com o atributo gênese, com o material classificado como residual. O atributo seguinte é a textura, que apresenta quatro opções, as quais são viáveis e ocorrem na área mapeada; portanto, todas recebem um "sim". Logo, o processo deve continuar a partir das quatro opções. Para efeito de exemplo, analisa-se a partir da textura silto-argilosa, que poderia teoricamente ocorrer em quatro diferentes espessuras, das quais somente duas estão presentes na área e as outras duas não. No caso das duas outras opções o processo de análise pára, pois não se observou na área nenhuma zona com material residual, textura silto-argilosa e espessura maior que 5,0 metros.

Entre as duas opções que receberam um "sim", utiliza-se a classe de espessura inferior a 0,5 metro para continuar a análise com o atributo declividade. Das oito classes de declividade existentes (classe $\mathrm{A} 1-<5 \%$ em mais que $85 \%$ de sua área; classe A2 - $<5 \%$ em 70 a $85 \%$ de sua área; classe B1 - 5 a $10 \%$ em mais que $85 \%$ de sua área; classe $\mathrm{C} 1->10 \%$, com valores superiores a $20 \%$ em menos que $25 \%$ da área; classe $\mathrm{C} 2->10 \%$ com valores superiores a $20 \%$, em 25 a $50 \%$ de sua área; classe C3 $>10 \%$, com declividades superiores a $20 \%$ em 50 a $75 \%$ de sua área e classe C4 - >10\%, com valores superiores a $20 \%$ em mais que $75 \%$ da área), em cinco delas ocorrem materiais com menos que 0,5 metro de espessura e em três não. A partir destas cinco, analisa-se a classe $\mathrm{A} 2$, que apresenta onze opções quanto às formações geológicas que poderiam ter originado este material inconsolidado. Da análise da região verifica-se que somente duas se confirmam, que são os magmatitos básicos pertencentes à Formação Serra Geral ou Suítes Básicas e as litologias da Formação Irati.

Portanto, no caso do exemplo, foram obti- 
Rev. IG. São Paulo, Volume Especial, 1995

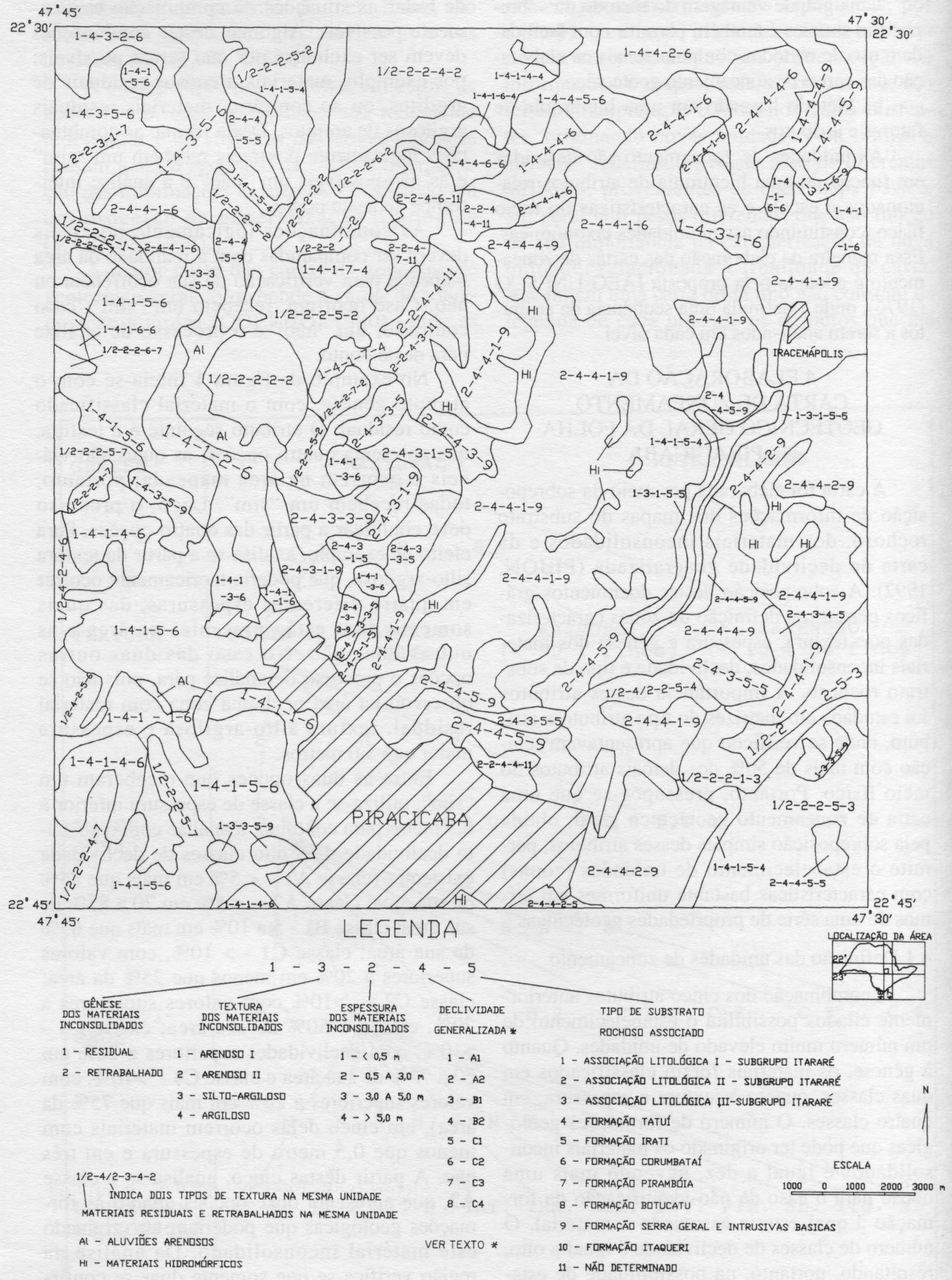

FIGURA 2 - Carta de zoneamento geotécnico geral da Folha de Piracicaba 
das duas unidades de zoneamento, que apresentam como única diferença as litologias que lhes deram origem. Este procedimento foi repetido para cada classe dos atributos, resultando em 107 unidades diferentes, que estão representadas na carta de zoneamento geotécnico geral. A figura 2 apresenta uma porção da área mapeada, correspondendo a uma área de aproximadamente $730 \mathrm{~km}^{2}$ (Folha de Piracicaba - escala 1:50.000).

As unidades obtidas diferem umas das outras pela variação de um ou até todos os atributos, motivo pelo qual se optou pelo uso de uma legenda numérica para identificar cada unidade, onde se registra a variação referente a cada atributo que lhe deu origem. Este tipo de legenda elimina a necessidade da utilização de contatos diferenciados, pois permite que se identifique com facilidade qual o atributo e/ou nível que está variando de uma unidade a outra. Mais uma vantagem deste tipo de legenda é permitir ao usuário que tenha um número maior de informações disponíveis sobre as características de cada unidade, uma vez que se trata de um zoneamento geral, sem finalidades específicas.

O zoneamento geotécnico geral tem grande importância em mapeamentos geotécnicos regionais, pois permite a associação de um número elevado de informações em uma única carta.

\section{CONSIDERAÇÕES FINAIS}

Esta carta destina-se aos técnicos familiarizados com a área de geotecnia e a interpretação das unidades deve ser feita com objetivos definidos, ou seja, para a elaboração de uma carta de zoneamento específico ou para a análise de um determinado tipo de ocupação do terreno. Assim, o zoneamento visando a uma utilização específica pode alterar a divisão atual. Por exemplo, duas zonas distintas poderão ter igual comportamento quanto ao escoamento superficial de água e diferente quanto a fundações. Isto se deve ao fato de o mesmo atributo poder apresentar maior ou menor importância, frente a diferentes tipos de uso do terreno.

Como a carta de zoneamento geotécnico geral reúne um grupo de atributos de grande importância na caracterização natural do meio físico, quase sempre poderá ser utilizada como base para a maioria das cartas de zoneamento geotécnico específico. A obtenção destas cartas depende da avaliação dos pesos dos atributos considerados, ou da análise de novos atributos diretamente relacionados à finalidade considerada.

\section{REFERÊNCIAS BIBLIOGRÁFICAS}

COELHO, A.M.L.G. 1980. A cartografia geotécnica no planejamento regional e urbano, experiência de aplicação na região de Setúbal. Tese apresentada ao concurso de especialista - LNEC. Lisboa, 157 p.

DEARMAN, W.R.; MONEY, M.S.; STRACHAN, A.D.; COFFEY, J.R.; MARDSEN, A. 1979. A regional engineering geological maps of the Tyne and Wear County, N.E. England. Bull. of the International Association of Engineering geology, Krefeld, (19): 5-17.

ERSHOVA, S.B. \& SERGEEV, E.M. 1979. Principles of the typological engineering geological zoning of the earth. Bull of the International Association of Engineering Geology. Krefeld. (19): 87-92.

HUMBERT, M. 1973. La carte géotechnique à 1:50.000 de Clermont-Ferrand (France) et la planification urbaine. Bull. B.R.G.M. (2), III, 3. p. 179-190.
IAEG-UNESCO 1976. Guide pour la préparation des cartes géotechniques. Paris. Les Presses de l'Unesco. 79 p.

PEJON, 1992. Mapeamento geotécnico da Folha de Piracicaba-SP (escala 1:100.000): estudo de aspectos metodológicos, de caracterização e de apresentação dos atributos. Tese de doutorado, Escola de Engenharia de São Carlos USP, 2 vols., $224 \mathrm{p}$.

RADBRUCH-HALL, D.H.; EDWARDS, K.; BATSON, R.M. 1979. Experimental engineering geologic maps of the conterminous United Stats prepared using computer techniques. Bull. I.A.E.G. (19): p. 358-363, Germany.

VARNES, D.J. 1974. The logic of geological maps, with reference to their interpretation and use for engineering purposes. U.S.A., Geological Survey - profissional paper $837,48 \mathrm{p}$. 